\title{
A Angústia Epistemológica na Psicologia
}

\author{
Ronie Alexsandro Teles da Silveira \\ Universidade de Santa Cruz do Sul \\ Simone Maria Hüning ${ }^{1}$ \\ Pontifícia Universidade Católica do Rio Grande do Sul
}

\begin{abstract}
RESUMO - Nesse texto, nos propomos a tratar do problema da diversidade epistemológica. Sua inspiração original pode ser identificada no que denominamos de "angústia epistemológica": a dúvida sobre que direção tomar diante da diversidade de opções hoje disponíveis no campo da Psicologia. O problema central que o caracteriza está ligado a como devemos enfrentar as diferenças existentes entre formas de se produzir conhecimento em Psicologia. Entendemos que é no limite entre a possibilidade e a impossibilidade do encontro e do diálogo que se pode construir o conhecimento em Psicologia, tomando o estranhamento, a diferença, a alteridade, como constitutivos da produção de conhecimento.
\end{abstract}

Palavras-chave: psicologia; produção de conhecimento; epistemologia.

\section{The Epistemological Anguish in Psychology}

\begin{abstract}
This paper aims at discussing the epistemological diversity issue. Its original inspiration may be identified in what we call "epistemological anguish": a doubt on which direction to take in view of the diversity of options available today in the field of Psychology. The main problem that characterizes it is related to how we must face the existent differences among forms of generating knowledge in Psychology. We understand that it is in the limit between the possibility and the impossibility of the meeting and the dialogue that one can generate knowledge in Psychology, taking the problem, the difference, the alterity as constitutive elements of the generation of knowledge.
\end{abstract}

Key words: psychology; generation of knowledge; epistemology.

É freqüiente que os estudiosos de uma disciplina rica em diversidade teórica tenham dificuldade para ter uma noção precisa acerca do significado do trabalho que realizam. Assim, a partir de um ponto de vista epistemológico particular (manifestado por uma escolha metodológica e teórica ${ }^{2}$ ), que eles têm de adotar no seu trabalho, surge a dúvida ligada a se estar ou não fazendo a "coisa certa". Eles pensam, então, se a escolha que foi feita é mesmo legítima e se não estariam, afinal de contas, tomando o "caminho errado" em meio à multidão de possibilidades em aberto fornecida pelas vertentes alternativas.

A partir de um quadro como esse é comum que se pense também que as demais opções teóricas (lembramos que são também opções epistemológicas), distintas daquela que foi escolhida, não passam de erros crassos, de más escolhas que foram feitas por outros pesquisadores a partir de pontos de vista equivocados. Essa posição sintetiza uma espécie de

1 Endereço: Pontifícia Universidade Católica do Rio Grande do Sul, Avenida Ipiranga, 6681, prédio 11 sala 930, Porto Alegre, RS, Brasil 90619-900.E-mail: nmguares@pucrs

2 Não há como pensarmos em uma separação entre as instâncias teórica, metodológica e mesmo ontológica, dos princípios epistemológicos adotados. Assim, no decorrer deste trabalho, a referência a questões como metodologia e teoria, não se faz com o intuito de cindi-las de um posicionamento epistemológico, apenas evidenciar as questões por meio das quais cotidianamente a academia põe em discussão o tema da epistemologia. vaidade intelectual que consiste em acreditar que todas as demais possibilidades não passam de equívocos cometidos por pesquisadores desatentos. Um modo de pensar como esse existe mesmo quando um pesquisador adota determinadas opções metodológicas (epistemológicas) apenas em função da conveniência ou do acaso. Isso ocorre, por exemplo, quando ele é "recrutado", em uma fase precoce de sua formação, para fazer parte de uma determinada comunidade científica sem ter, de fato, feito uma escolha autêntica ou qualquer reflexão sobre as possibilidades e implicações de outras opções epistemológicas. Entendemos que uma escolha autêntica é aquela que é feita a partir do conhecimento prévio das diferenças existentes em uma constelação de alternativas científicas.

No caso de recrutamento, uma avaliação adequada dos pressupostos com os quais um pesquisador trabalha somente poderá ser feita muito mais tarde e na medida em que ele se tornar tão apto a manusear as categorias usuais de sua comunidade científica a ponto de colocá-las sob suspeita. Essa estranha situação de ausência de condições para fazer escolhas antes do processo de treinamento científico no uso de um conjunto de categorias particular é a prática corrente no mundo acadêmico - desde os mecanismos de iniciação científica até a formação de grupos de pesquisa na pósgraduação. Com efeito, quem está sendo recrutado ainda não possui condições de submeter a linguagem científica usual a uma crítica severa. Um pesquisador só se torna apto para isso muito tempo depois.

Que o reconhecimento da diversidade epistemológica somente ocorra (quando ocorre!) após a instrumentalização do 
pesquisador em um tipo de linguagem particular, típica de sua comunidade, parece ser mesmo o curso natural das coisas. $\mathrm{O}$ que nos interessa aqui é ressaltar que o confronto com opções epistemológicas (teóricas, metodológicas, ontológicas, éticas, políticas...) distintas daquela em que estamos imersos, por escolha ou por conveniência, é um evento muito comum na vida intelectual de um pesquisador, embora tardio. Porém, a experiência dessa diversidade somente poderá ser feita se, em algum momento, ele suspeitar da própria vaidade intelectual e da certeza sobre a linguagem que usa. Isso implica em não resolver a questão da diversidade apelando rapidamente para a noção de que todas as alternativas teóricas, que não a sua própria, são somente erros. Ou seja, a experiência da diversidade exige a superação da vaidade intelectual.

Outra maneira de enfrentar a diversidade de possibilidades epistemológicas, além da negação produzida pela vaidade intelectual, é imaginar que deveria ser feito um esforço para aproximar a diversidade de opções existentes. Um esforço de convergência como esse pretende estabelecer algum tipo de linguagem unificada que permita, ao final, uma compreensão geral de todas as perspectivas epistemológicas disponíveis em uma grande moldura teórica. Essa segunda perspectiva exige dois passos distintos.

Em primeiro lugar, a própria noção de construir uma modalidade de convergência epistemológica pressupõe o abandono daquela vaidade intelectual centrada em uma das linguagens científicas específicas. Isso significa empenharse em estabelecer uma perspectiva de unificação para além da teoria que nos recrutou originalmente. Isso não significa necessariamente uma violência contra as teorias divergentes e, pelo menos na aparência, mutuamente excludentes. Essa unificação pode significar somente um enquadramento metateórico que abrigue e dê sentido à própria diversidade.

Em segundo lugar, é necessário tornar viável uma linguagem que, de alguma forma, abrigue em si a diversidade das teorias vigentes sem resvalar novamente para a unilateralidade da vaidade intelectual - evitando uma posição totalitária ou intransigente. Temos, portanto, uma dificuldade pessoal no que diz respeito a reconhecer as limitações da linguagem científica na qual fomos educados, a superação da vaidade intelectual, e uma dificuldade "objetiva" no sentido de tentar construir uma linguagem das linguagens ou um metarrelato para abrigar a diversidade epistemológica em questão.

Essas duas dificuldades estão presentes no trabalho de produção do conhecimento em Psicologia. Com efeito, a diversidade de perspectivas existentes na Psicologia fica evidente se observarmos que o espectro hoje disponível envolve, por exemplo, desde posições teóricas muito próximas da Sociologia e da Antropologia (a Psicologia Social), até outras perspectivas limítrofes às questões biológicas, como aquelas ligadas à base neurológica dos fenômenos cognitivos (a Psicologia Cognitiva). A pluralidade apresenta-se nitidamente também no plano metodológico entre opções qualitativas, quantitativas, as que se propõem a ser, de algum modo, mistas e aquelas que não se enquadram nestas classificações, como as propostas por vertentes pós-estruturalistas e pós-modernas.

Se, porventura, o panorama epistemológico, evidenciado neste caso especialmente pelas questões teóricas e metodológicas da Psicologia, mostrasse uma maior unidade, con- vergência e simplicidade, certamente as questões ligadas ao manejo da diversidade não se apresentariam de maneira tão intensa e nem seriam percebidas, na prática do trabalho intelectual, como tão decisivas. Entretanto, esse não é o panorama real. O que se observa é a ampliação gradativa da diversidade de alternativas epistemológicas e, concomitantemente, dos impasses e tensões que acompanham tal diversidade.

Neste texto, nos propomos a tratar do problema da diversidade epistemológica e das questões que preocupam os pesquisadores em Psicologia que, de uma maneira ou outra, têm de fazer suas opções no calor da peleja do trabalho intelectual. Sua inspiração original pode ser identificada no que denominamos de "angústia epistemológica": a dúvida sobre que direção tomar diante da diversidade de opções hoje disponíveis no campo da Psicologia. Obviamente, essa angústia é uma consequiência da superação da vaidade intelectual a que nos referimos. O problema central que a caracteriza está ligado a como devemos enfrentar uma diferença existente entre ao menos duas maneiras quaisquer de fazer ciência - no caso, duas ou mais formas de se produzir conhecimento em Psicologia. A angústia epistemológica é decorrente, portanto, de nossa incapacidade de nos orientarmos no panorama geral do conhecimento em face de sua diversidade.

\section{Fundamentação pelo Metarrelato}

A Filosofia tem historicamente se ocupado com a formulação de grandes molduras teóricas que permitem uma orientação no sistema geral do conhecimento humano. Aristóteles foi o primeiro a tentar sistematizar as diferentes maneiras de conhecer em uma totalidade ordenada. Ele estipulou uma hierarquia de todas as formas de conhecimento com base em uma suposta hierarquia existente no mundo. Ele dizia que é sinal de um homem versado nas ciências não exigir de cada uma delas senão o grau de precisão relativo à natureza do seu objeto (Aristóteles, 330a.c./2001). Ou seja, haveria uma forma de conhecimento correspondente à posição hierárquica do objeto no mundo. Isso produziria uma hierarquia epistemológica derivada de uma hierarquia ontológica. Dessa maneira, poderíamos saber se uma maneira de conhecer é epistemologicamente superior a uma outra e ter uma visão panorâmica da totalidade de todas as ciências.

De fato, por meio dessa estratégia, obtemos uma visão de conjunto e também uma maneira para resolver problemas gerados pela diversidade epistemológica. Através dela, e diante de um quadro de angústia epistemológica como o que caracterizamos acima, podemos buscar identificar a posição hierárquica de cada opção existente e então decidir qual é superior e qual é inferior. Certamente, por meio dessa estratégia aristotélica, não estaremos fazendo uma distinção entre falsas e verdadeiras opções e sim entre opções providas de algum tipo de privilégio epistemológico e outras menos favorecidas a esse respeito. Assim, evitamos a tentação da vaidade intelectual e fundamos um metarrelato acerca do conhecimento humano em geral, que descreve a relação entre as linguagens científicas particulares.

Em outras palavras, essa estratégia aristotélica parece permitir resolver o problema da diversidade que nos angustia indicando um lugar específico para cada forma de conhecimento dentro de uma hierarquia geral. Assim, ela 
nos conduz a identificar se estamos trabalhando com uma teoria privilegiada epistemologicamente e, portanto, obter um apoio decisivo para ter certeza de que nossas opções foram mesmo feitas de maneira fundamentada e não somente em função do nosso recrutamento precoce por uma comunidade científica.

A angústia epistemológica parece se dissipar, portanto, na medida em que somos capazes de determinar o lugar específico de cada teoria dentro de um sistema mais amplo que engloba a diversidade de opções existentes. Portanto, nos termos de Aristóteles, podemos encontrar uma aparente solução para os problemas que nos afligem em nosso trabalho de pesquisa em Psicologia quando adotamos um critério que garante legitimidade por meio da constituição de uma hierarquia dos modos de conhecer.

Observe que o critério aristotélico da hierarquia existente no mundo é de caráter cosmológico. Isto é, resolvemos a angústia epistemológica que nos afligia apelando para certo conjunto de crenças sobre o mundo físico. É justamente em função da hierarquia ontológica que Aristóteles postula uma hierarquia para as formas de conhecimento e é essa, por sua vez, que julgamos poder debelar nossa angústia.

Entretanto, esse modelo não nos serve mais depois que começamos a crer que o universo era infinito. A transição histórica da antiga concepção de "cosmos" (um mundo finito e hierarquicamente ordenado) para uma concepção moderna de "universo" (um mundo infinito e sem hierarquia) foi descrita por Koyré (1957/2001). Assim, podemos constatar a inutilidade do dispositivo aristotélico com relação aos nossos propósitos em função do abandono cultural da noção de uma hierarquia fundada na idéia de "cosmos".

Com efeito, do ponto de vista que nos interessa, a mudança de nossas crenças sobre o mundo físico acarreta o fracasso da estratégia aristotélica para ordenar os diversos tipos de conhecimento e, dessa forma, fornecer um alívio para a angústia epistemológica em Psicologia. Se as coisas não ocupam uma posição particular natural em um mundo finito, se não há como se assegurar que algumas delas sejam ontologicamente melhores que outras, também não temos como obter garantias de que suas respectivas formas de conhecimento também o sejam. Terminamos perdendo, então, aquela perspectiva privilegiada de uma visão panorâmica do conjunto de todas as formas de conhecimento baseada na antiga hierarquia de um mundo finito e ordenado. E, dessa forma, recaímos em nossa conhecida sensação de angústia epistemológica.

Outra tentativa de sistematizar e ordenar as diferentes formas de conhecimento foi feita por Hegel (1817/1970) através de um artifício que chamamos de "enciclopédico". Ele entendia as diferentes formas de conhecimento como etapas de um mesmo desenvolvimento em direção à autoconsciência completa e definitiva do espírito ${ }^{3}$. Com base nessa idéia, ele podia articular cada forma de conhecimento particular, cada

3 Não nos interessa aqui discutir o conceito de autoconsciência, mas apenas verificar sua função de articular as formas de conhecimento em uma seqüência que, para Hegel, implica no desenvolvimento do conhecimento que o Espírito formula para si mesmo. ciência, como uma etapa determinada desse trajeto - logo, cada uma delas possuía um lugar fixo no caminho para a realização dessa autoconsciência.

$\mathrm{O}$ artifício hegeliano está ligado à construção de um metarrelato. Isto é, trata-se de uma estratégia que lança mão explicitamente de uma linguagem sobre as várias formas particulares de conhecimento. A necessidade de que se deve fundamentar uma ciência em uma instância epistemológica superior é idêntica à estratégia hegeliana para criar uma enciclopédia geral das ciências - o metarrelato hegeliano chama-se "Enciclopédia das Ciências Filosóficas" (Hegel, 1817/1970). "Fundamentar" significa, nesse caso, vincular esse saber particular a um saber de perspectiva mais ampla e universal - como uma grande moldura que nos permite ordenar a diversidade de formas de conhecimento particulares.

Sabemos que uma enciclopédia é a reunião de todo o conhecimento disponível sobre determinado(s) assunto(s). Entretanto, diferentemente da organização alfabética de uma enciclopédia convencional, a ordem da enciclopédia hegeliana está ligada à contribuição de cada forma de conhecimento para a formação da autoconsciência do espírito. Nesse sentido, ela se constitui como uma instância epistemológica superior responsável por consignar a cada ciência seu lugar no sistema completo do conhecimento. Todas as formas de conhecimento estariam articuladas como membros desse grande sistema e, portanto, saberíamos qual o lugar e a importância de cada um deles.

Uma vantagem evidente de tal sistema enciclopédico é que escapamos da dificuldade do sistema aristotélico, pois não importamos um critério de fora (vindo do mundo físico) para dentro do âmbito do conhecimento. O critério de organização do sistema hegeliano é definido pelo próprio sistema e pelas suas necessidades imanentes: a contribuição de cada forma de saber para o saber absoluto ou para a autoconsciência do espírito.

Por meio do recurso enciclopédico hegeliano, a angústia epistemológica parece novamente se dissipar na medida em que seria possível indicar a cada forma de conhecimento seu lugar específico na marcha do espírito em direção à sua autoconsciência. O lugar que cada forma de conhecimento ocupa no sistema de saber em geral está ligado a essa forma de consciência que é oferecida ao espírito por cada conhecimento específico. Essa visão panorâmica, fornecida pela enciclopédia, permitiria colocar cada conhecimento no seu devido lugar. Dessa forma, saberíamos o que significa fazer Psicologia da maneira como fazemos ou em que posição nos encontramos quando nos vinculamos a certa comunidade científica específica. Isso levaria, portanto, ao fim da angústia que nos atormenta.

Entretanto, em nossa época, a percepção da necessidade de se constituir metarrelatos entrou em decadência. Isso conduziu a uma série de reflexões acerca da produção do conhecimento científico que provocaram importantes mudanças nos modos de se pensar a ciência. Com essas alterações, a própria ciência passou a ser questionada naquilo que lhe asseguraria um estatuto de verdade e se produziram questões sobre diferentes epistemologias, metodologias e a insustentabilidade das hierarquizações das formas de saber. Uma descrição desse estado de coisas pode ser encontrada no pensamento de Lyotard (1979/2002). Para ele, uma das con- 
dições do mundo em que vivemos se caracteriza justamente pela descrença de que a legitimação do conhecimento precisa se operar em uma outra instância superior que forneça uma fundamentação para a inferior. Segundo Lyotard, tornou-se simplesmente desnecessário obtermos um ponto de apoio ou uma visão panorâmica a partir do qual possamos articular a diversidade das formas de conhecimento.

Note, entretanto, que Lyotard não está defendendo uma tese que afirma que devemos adotar esse ponto de vista que nega a importância dos metarrelatos. Isso definitivamente não é uma tese para ele. Na sua perspectiva, trata-se antes de um aspecto prático do modo atual de se produzir conhecimento em que as formas particulares se libertaram do sistema geral do saber. Isto é, a produção de conhecimento existente não faz mais referência a uma instância reguladora simplesmente porque tal legitimação não é mais considerada necessária na prática de sua produção. Ao invés disso, o status de "conhecimento legítimo" estaria vinculado a questões econômicas (por exemplo, nos financiamentos de pesquisas), políticas (constituição de uma comunidade de interlocutores que validem a relevância do que e como deve ser pesquisado) e culturais (efeitos de verdade articulados a diferentes modalidades discursivas). Esses aspectos práticos a que fazemos referência estão ligados, portanto, à maneira como a ciência é produzida e não à discussão sobre como a ciência deveria ser produzida.

\section{Organicidade e Legitimação Imanente}

Há um importante aspecto dessa mentalidade contemporânea relativa à produção do conhecimento que não pode ser menosprezado. Há uma crença generalizada de que muitas "aberrações" teóricas na Psicologia são devidas à falta de reflexão epistemológica. Assim, por exemplo, graves problemas atuais ligados a ecletismos teóricos, à desvinculação entre as teorias e as práticas psicológicas ou ainda à formação de profissionais poderiam ser resolvidos com uma adequada fundamentação epistemológica. Essa perspectiva parte da noção de que a discussão epistemológica no campo da Psicologia tem sido injustamente relegada a um plano secundário. Isso teria provocado uma cisão entre a produção do conhecimento e as práticas psicológicas. Ou seja, para essa perspectiva, a ruptura entre os modos de conhecer e os modos de intervir em Psicologia seria causada por um encolhimento indevido do papel da epistemologia.

Esse modo de entender a situação atual de produção do conhecimento postula que a epistemologia constitui-se como uma instância responsável por estipular critérios de aceitação do que é cientificamente legítimo. Mais do que isso, além dos critérios, ela deveria cuidar para que houvesse certa organicidade interna aos modelos teóricos de tal maneira que, de postulados epistemológicos adequados, poderíamos inferir propostas metodológicas condizentes.

Essa noção, que requisita alguma instância epistemológica a partir da qual a organicidade para a Psicologia pode ser fundada, pode ser identificada nas exigências de Canguilhem (1999), por exemplo. Quando ele afirma que nem uma ciência, nem uma técnica científica contêm, elas mesmas, uma idéia que lhes confira sentido, está afirmando a necessidade de alguma outra instância reguladora responsável por ele.
Trata-se de requisitar um critério de legitimidade para além da própria prática científica: um tribunal epistemológico que, de alguma maneira seria independente da atuação de uma comunidade científica que produz conhecimento. E é justamente essa independência que garantiria a objetividade requerida.

Assim, em um sentido clássico, a epistemologia seria responsável por estabelecer pontes sólidas que nos levariam dos seus próprios princípios para a metodologia da produção do conhecimento e também para a elaboração de princípios práticos diretamente conectados à prática psicológica. Seriam as concepções fundamentais de realidade e de sujeito que nos levariam a aceitar e a formular determinadas teorias e propormos metodologias específicas de acesso àquelas dimensões. E seriam essas mesmas dimensões ontológicas e epistemológicas que nos propiciariam um arcabouço ético e político para orientar a prática do trabalho psicológico.

Se a Psicologia não retira de tais princípios esses efeitos, ela está relegando a epistemologia - ou qualquer narrativa sobre os princípios mais gerais - a uma instância menos importante do que aquela que lhe seria de direito. Portanto, a Psicologia estaria negligenciando as discussões epistemológicas que deveriam estar sendo feitas. Essa situação estaria gerando uma espécie de vale-tudo teórico e metodológico e também conduzindo a certa crise de fundamentação em questões éticas e políticas no âmbito da prática psicológica.

Essa tese "organicista" (porque exige organicidade entre princípios teóricos gerais ou valores e a configuração de uma prática científica) com relação ao papel da epistemologia na produção do conhecimento entende que a situação atual é inadequada e injusta e que ela deveria ser retificada. Sua causa principal parece ser que os psicólogos não refletem o suficiente sobre sua própria atividade e, por isso, geram propostas sem a devida articulação com os princípios fundamentais. A solução para esse estado de coisas parece indicar que os psicólogos deveriam fundamentar melhor suas práticas de intervenção e de produção do conhecimento em princípios epistemológicos e ontológicos mais gerais.

Nessa perspectiva organicista e clássica da epistemologia estaríamos - porque não dizê-lo - diante de uma crise de superficialidade da Psicologia. Basicamente, o problema da tese organicista não está na sua reivindicação por legitimidade ou de objetividade e sim na crença de que há apenas uma boa via epistemológica. O exclusivismo que ela advoga termina por implicar, equivocadamente, que há um modo privilegiado que deve ser observado se queremos obter objetividade e legitimidade.

Não acreditamos que essa maneira organicista de pensar que reserva um lugar de destaque para o papel da epistemologia tenha sentido atualmente. Não se trata de uma constatação baseada em uma refutação teórica de que ela é equivocada ou impossível - no mesmo sentido da tese de Lyotard. Trata-se, isso sim, de verificar que na prática, cada vez menos, os critérios epistemológicos universais de legitimação são usados. Ou seja, a questão é que há uma tendência crescente na produção de conhecimento em deixar de lado o status quo de uma cientificidade baseada em critérios universais em benefício de critérios particulares (Latour, 2001). Há um processo de substituição da transcendência dos critérios epistemológicos tradicionais por critérios imanentes à prática científica. $\mathrm{Ou}$ 
seja, justamente aquilo que Ganguilhem criticou como defeito da Psicologia, tornou-se uma virtude: a fragmentação e a democratização dos valores epistemológicos.

O que estamos dizendo é que há um processo que torna gradativamente independentes as próprias instâncias epistemológicas de produção do saber (veja que já não se trata de uma, mas de várias), de tal forma que elas passam a retirar a legitimidade de sua própria maneira de atuar. Elas deixam de procurar seus fundamentos em uma instância superior que forneça suas bases e passam a reconhecer na sua prática a capacidade para gerar a própria legitimidade.

Trata-se, portanto, de um outro sentido para a noção de fundamentação epistemológica e da própria epistemologia distinto daquela noção clássica. Nesse sentido, é necessário enfatizar que não se trata do fim da epistemologia e sim da passagem da uma epistemologia clássica universal, para uma diversidade de perspectivas epistemológicas que geram legitimidades a partir da prática do trabalho científico.

Assim, se aquela maneira tradicional de pensar requeria uma organicidade e, portanto, a transmissão de um valor de verdade oriundo de princípios ontológicos e epistemológicos até o "reino inferior" da ética e da política, isso não é mais necessário. É justamente a prática da produção do conhecimento que se tornou decisiva para a definição de seus critérios de legitimação. Esses critérios são imanentes à própria prática, bem como às dimensões ética e política, que deixam de ser "conseqüências" para situarem-se no mesmo plano da produção teórica. Dessa maneira, diferentes ontologias e diferentes epistemologias são igualmente resultados de práticas científicas distintas.

Entretanto, não se trata de ratificar tudo o que é feito em Psicologia pela mera desconsideração de princípios epistemológicos gerais, mas sim de adotar uma postura que entende que nada pode ser feito que não tenha o apoio e o reconhecimento de uma comunidade relativamente autônoma de pesquisadores (Latour, 2001; Rorty, 1991/1997). Assim, para obter legitimidade, uma crença deverá passar pelo crivo da formação de consenso no interior dessa comunidade. E essa é uma questão das práticas científicas e não uma questão epistemológica naquele sentido tradicional que a perspectiva organicista exigia.

Podemos pensar que há, obviamente, virtudes éticas e políticas que uma comunidade que procura formar algum consenso deveria ter: não fazer uso de argumentos de autoridade, submeter teorias adversárias ao crivo de uma discussão aberta e sem preconceitos etc. Todos eles levam a pensar que uma boa maneira de elaborar um conhecimento robusto é aquela adotada por comunidades científicas democráticas (Rorty, 1991/1997). Essas não possuem nenhuma virtude epistemológica especial, nenhuma varinha de condão responsável por gerar legitimidade, nenhuma perspectiva privilegiada. Trata-se somente de que, produzindo consensos por essa via, eles tendem a ser mais democráticos e, nesse sentido, mais legítimos.

Esse diagnóstico da maneira como o conhecimento é produzido está muito próximo da falência dos metarrelatos a que Lyotard (2002/1979) faz referência. Porém, a situação de insegurança causada por essa falência pode conduzir - e, de fato, julgamos que isso tem ocorrido - a uma busca por estabilidade junto à dimensão metodológica do conhecimen- to. Assim, o ponto fixo que garante convergência e solidez à prática científica passa a ser a utilização de uma mesma metodologia. Com efeito, é cada vez mais comum que a instrumentalização de pesquisadores passe pela capacitação no emprego do método já utilizado por uma comunidade científica sem que isso envolva alguma reflexão epistemológica em qualquer sentido.

Não queremos dizer com isso que a falência dos metarrelatos explica a ênfase contemporânea no método, embora ela gere uma sensação de insegurança que pode vir a ser equivocadamente solucionada por meio da aparente fixidez oferecida pela utilização de uma metodologia padrão. Julgamos, portanto, que muito do apego contemporâneo ao método como constituinte principal da prática na produção do conhecimento é gerado pela busca por um ponto sólido que a epistemologia não pode mais oferecer. Como o céu sobre nossas cabeças não oferece mais pontos fixos que nos permitam uma orientação satisfatória, passamos a procurá-los dentro de nós. Nesse sentido, corremos o risco de somente legitimar o status quo metodológico da prática científica na medida em que ele, pela sua própria natureza, constitui-se como algo estável. Parece-nos que é nessa crise relativa aos critérios de legitimação interna às comunidades científicas que a prioridade do método tem se assentado.

Note-se que o uso do método como legitimador da prática científica reforça o exclusivismo e a vaidade intelectual e não gera nenhum tipo de angústia ou dúvida com relação ao tipo de atividade que está sendo desenvolvida no trabalho intelectual. Dessa maneira, julgamos que a atitude contemporânea de priorizar o método em detrimento de discussões epistemológicas (no sentido da imanência que estamos defendendo) é danosa por não propiciar nenhuma dúvida com relação à exclusividade do processo de produção do conhecimento.

Se analisarmos com cuidado nossa sensação de angústia epistemológica, notaremos que ela talvez seja um indício de uma maneira "pré-pós-moderna” de pensar. Isto é, parece ficar claro que a angústia é causada por requisitarmos uma solução para a diversidade, uma ordenação para o caos causado pelas diferenças irredutíveis entre opções epistemológicas. E essa requisição para resolver a angústia da diversidade que postulamos é justamente o que Lyotard diz que o modo atual de produzir conhecimento não parece mais necessitar. Portanto, tudo leva a crer que nossa angústia epistemológica é um sintoma de uma maneira de pensar moderna dentro de um modo de produção do conhecimento pós-moderno. Isto é, ela seria uma característica de indivíduos fora de sintonia com a sua própria época - resquícios saudosistas de um tempo que já terminou.

Mais cuidadosamente, notamos que o que parece perdido na condição pós-moderna, na perspectiva de Lyotard, é um ponto de vista universal a partir do qual possamos compreender e fundamentar a totalidade das diferentes formas de conhecimento. Enfim, parece que não temos mais uma montanha sobre a qual subir e olhar a diversidade das formas de vida que se desenrolam no vale lá embaixo - estamos simplesmente colocados em uma planície epistemológica em que predomina a diversidade pura e simples. Não temos, portanto, um terceiro ponto de apoio a partir do qual podemos articular as diferenças entre ao menos duas formas de conhecimento distintas. Isso significa que não temos como 
sair de nossa própria condição epistemológica para avaliar a relação dela com as demais. Não temos como atravessar aquilo que nos constitui para chegar ao outro e nem condições de tornar possível uma metalinguagem que funcione como instância legitimadora de todas as outras linguagens. Em outras palavras, trata-se da nossa dificuldade de aprender a viver na ambivalência (Bauman, 1999) que caracteriza o mundo contemporâneo.

Mas, mesmo na planície, mesmo considerando a incapacidade de ultrapassar nossa condição epistemológica, podemos caminhar e encontrar a diferença. Obviamente, não podemos subir em nada que não seja nossa própria perspectiva para olhar mais longe. Porém, se dosarmos nosso insuperável etnocentrismo (Rorty, 1982/1996) com uma boa dose de disposição, podemos encontrar formas diferentes de conhecimento. Entretanto, jamais poderemos deixar de ser o que somos como estratégia para entender o outro. Note, entretanto, que esse movimento é horizontal e não vertical como as iniciativas de Aristóteles, de Hegel e da perspectiva organicista que descrevemos indicavam.

Se não temos condições epistemológicas de considerar as diferentes formas de conhecimento a partir de uma perspectiva superior, nos resta somente a disposição para nos entendermos a partir daquilo que constitui nossa especificidade. Não há, estritamente falando, pontos de vista epistemologicamente especiais que nos assegurem uma perspectiva privilegiada para ordenar um sistema do saber em geral.

Assim, essa disposição é um componente ético que interfere diretamente em nossas disposições epistemológicas. Como não temos pés de apoio epistemológicos em um sentido organicista e fundante, resta-nos o substituto ético da possibilidade de entendimento entre diferentes posições teóricas. Na verdade, a discussão epistemológica tem de ser convertida aqui em um problema de disposição ética para o entendimento no seio da diversidade e para a formação do diálogo.

Uma convicção ética desse tipo é claramente favorecida por modos de vida democráticos, como dissemos. Isto é, por condições políticas de vida nas quais temos que nos entender com outras pessoas que pensam de maneira diferente de nós. Nesse sentido, a cultura presente em algumas comunidades científicas tem muito a nos ensinar na medida em que, a princípio, elas parecem se estruturar como um debate honesto em que não devem prevalecer questões de autoridade de nenhuma espécie (Rorty, 1991/1997).

\section{A Planície da Diversidade e do Diálogo}

Estritamente falando, não vemos como o desejo de obter um conhecimento sistemático que resolva a angústia epistemológica possa se favorecer de algum artefato teórico que nos lance para um ponto de vista superior no sentido que indicamos. Não parecem existir nem catapultas nem elevadores epistemológicos que nos lancem para tais lugares privilegiados. Entretanto, a construção de pontes entre constituições epistemológicas diferentes pode ser concretizada se tivermos em mente que elas são questões de disponibilidade ética e ação política e não questões de privilégio epistemológico no sentido clássico.

Uma maneira infrutífera, na nossa perspectiva, de fazer referência à possibilidade de enfrentar a questão da diversi- dade epistemológica está intimamente ligada ao realismo. Vamos utilizar aqui um exemplo da suposta oposição entre as metodologias quantitativas e qualitativas para evidenciar a presença das noções realistas no contexto do tratamento da diversidade epistemológica e metodológica. Ficará claro como tal posição não favorece a elaboração de boas soluções para a angústia epistemológica.

Em geral, as opções metodológicas são colocadas em termos de oposição ou de combinação entre os métodos quantitativos e qualitativos. Como a oposição entre elas parece limitar o estudo a somente um dos aspectos da realidade, em geral se busca promover alguma união entre elas. Com essa combinação, supostamente se obteria uma melhor visão do objeto de estudo pretendido por meio de uma ampliação da perspectiva. Mas isso somente poderia ocorrer se compreendemos que o que é apreendido por cada uma dessas metodologias se origina de alguma coisa em comum, de algo que está dado de maneira unificada no mundo antes de nossa tentativa de conhecer. Então, poderíamos sintetizar o resultado desses dois tipos de estudo de tal forma que a soma resultante seria melhor que as partes isoladas. Nesse sentido, a adição de duas maneiras de ver algo - uma maneira de ver quantitativa e uma maneira de ver qualitativa, por exemplo - é sempre melhor do que uma maneira apenas.

Mas essa soma só pode ser efetuada se houver mesmo uma base comum para os resultados parciais de nossas apreensões geradas pelas diferentes opções metodológicas. Isto é, a soma vai depender de haver algo real aquém de nossa condição epistemológica, uma realidade que independeria dos nossos modos de conhecer (seja ela sensível e ligada àquilo que percebemos com nossos sentidos, seja ela metodológica e ligada ao resultado a que chegamos em função de adotarmos recursos quantitativos ou qualitativos). Ou seja, para somar um valor (qualitativo) com o outro (quantitativo) temos de possuir um ponto de referência comum que necessita ser diferente de tudo aquilo que podemos obter por meio do uso das diferentes metodologias. Isso exige uma referência externa fixa, um elemento da realidade que não pode depender em nenhum sentido do nosso modo particular de conhecer.

Para garantir que uma coisa assim exista, algo externo e real que nos forneça aquela unidade de medida, teríamos que nos apropriar dele para aquém de nossas condições de conhecer qualquer coisa. Mas como poderíamos conhecer algo justamente abrindo mão de nossas condições para conhecer? Não acreditamos que isso seja possível se pretendemos dar um passo adiante da mera postulação de uma entidade que estaria lá, mas da qual nada poderíamos saber. Quando hipoteticamente abstraímos nossas condições de conhecer as coisas, não nos colocamos em uma perspectiva superior para conhecer. Pelo contrário, com isso apenas nos tornamos incapazes de conhecer qualquer coisa.

O realismo implica, portanto, na busca por algum ponto de vista superior abstrato e fora das nossas próprias condições epistemológicas. Dessa maneira, ele dificulta a noção de que a legitimação do conhecimento passa pelo embate no interior de uma comunidade científica e reforça a perspectiva que busca um ponto de apoio metafísico para validar o saber.

Julgamos que o desejo de se obter uma linguagem epistemológica única para a Psicologia constitui em não mais que um sonho que não nos parece trazer qualquer contribuição 
relevante se fosse realizado. Isso porque, a unicidade poderia tender a assumir uma postura totalitária de unificação e, portanto de aniquilação das diferenças.

Ao invés de uma linguagem única, talvez pudéssemos pensar em estratégias de diálogos que se constituiriam por meio de movimentos laterais, isto é, como uma tentativa de entendermos e falarmos outras linguagens a partir da linguagem que falamos. Afinal, porque aprendemos uma língua estrangeira senão para entender a cultura e o conhecimento daqueles que são diferentes de nós e para nos aproximarmos de sua cultura? Isso, no entanto, não implica abandonarmos nossa própria língua e nossa cultura. A estratégia de estabelecer fóruns horizontais de diálogo, ainda que pareça difícil de ser realizada, em função da crescente e cada vez mais complexa produção do conhecimento e do acirramento das disputas entre as diferentes posições paradigmáticas da ciência pode ao menos indicar uma direção promissora. Essa estratégia é tanto mais promissora se considerarmos que, dado a diversidade de pontos de vista, só nos resta tentarmos nos entender mutuamente.

Com efeito, depois do advento da Torre de Babel só nos resta mesmo tentarmos nos entender uns aos outros a partir da linguagem que falamos. Isto é, construir novas maneiras de falar que sejam significativas para um grande número de pessoas e que leve em consideração seu modo de falar atual. De nada adianta ter saudades das míticas épocas paradisíacas em que nos entendíamos mutuamente de maneira perfeita. A diversidade está posta e nos cabe inventarmos modos de relações que possibilitem a troca sem a imposição ou a simples destruição da diferença. No campo científico, isso remete à aceitação de critérios de "regulação" que impliquem diálogo e democracia. Esses critérios estão para além de critérios unicamente epistemológicos e adentram no campo ético e político.

Se um dia pudermos nos sentar com nossos antípodas na tentativa de chegar a um acordo, estaremos promovendo um espaço de diálogo que deverá, como tal, ser mediado pela negociação e talvez pelo consenso. Mas sonhar com um ponto de unificação que não passe por negociações com aqueles que falam linguagens diferentes somente irá gerar mais antípodas radicais e sem fé no entendimento mútuo - pessoas que não crêem na possibilidade de diálogo simplesmente porque as condições instituídas os levam a acreditar que eles não serão ouvidos a partir de sua própria perspectiva. Se o que se busca é a chave que nos dará acesso a alguma modalidade de verdade, então esta última se encontra na dependência de um debate que está por ser feito.

Paradoxalmente, o diálogo e o resultante entendimento entre as diferentes linguagens científicas e metodológicas somente poderão acontecer frente ao reconhecimento da limitação da própria linguagem que usamos e se nos dispusermos a contrabalanceá-la com boa vontade para nos entendermos. Mas se acreditarmos que é o nosso modo de usar a linguagem que verdadeiramente diz como as coisas são na realidade ou que temos algum tipo de acesso epistemológico privilegiado, então não temos nenhum motivo para negociar ou dialogar.

Nessa perspectiva, temos motivos apenas para fazer com que aqueles que estão errados - pois falam a linguagem errada - saiam do engano e se convertam ao uso da nossa. Para quem vê as coisas assim, sob um prisma realista, só pode haver rendição (ainda que civilizada), mas não acordos. Esse modo de pensar está ligado à conversão e à rendição dos infiéis e não à formação de acordos. Acordos são entendidos aqui não como redução a um ponto de vista único, mas como possibilidade de diálogo e de oposição, produção de alteração recíproca.

\section{Conclusão}

Quando nos indispomos com quem fala linguagens diferentes da nossa, quando agimos com má vontade com relação às alternativas teóricas ligadas aos nossos estudos ou simplesmente quando dizemos "Isso não é da minha área!" para evitar uma discussão, estamos nos recusando a construir as possibilidades para acordos futuros e nos negando a promover o diálogo. O sonho de unificação e de consenso pode até mesmo parecer louvável e se tornar desejável. Mas a força contrária também precisa ser mantida: a capacidade de criar novas maneiras de falar e formas alternativas de pensar que possam dar origem e fazer a acolhida das diferenças (Amorim, 2001). Com efeito, são essas novas maneiras de falar que poderão vir a se constituir como futuros diálogos polifônicos. Sem a produção da diferença, eliminamos também a possibilidade de novos e melhores acordos no campo da produção do conhecimento. Assim, temos que assegurar também a possibilidade de que as diferenças se estabeleçam mesmo que elas não pareçam importantes no momento da sua origem.

A angústia epistemológica pode ser melhor assimilada se pensarmos que o que ela nos oferece é uma excelente oportunidade de produzirmos diálogos que nos levem para posições diferentes das que estão instituídas agora. Se a representarmos como algo que deve ser eliminado a todo custo, estaremos promovendo as posições realistas e a vaidade intelectual - que aparece quando imaginamos que há mesmo um ponto de vista definitivamente privilegiado. Então, uma boa estratégia para enfrentar nossa angústia é simplesmente deixar que ela se mostre de maneira completa. Isso significa que devemos valorizar a diversidade teórica e metodológica e não abominá-las.

É no limite entre a possibilidade e a impossibilidade do encontro e do diálogo que se pode construir o conhecimento no campo da Psicologia. O estranhamento, a diferença, a alteridade, são constitutivas da interrogação e da perplexidade e, portanto, da produção de conhecimento. Eles são, em última instância, condições para a própria existência da ciência. Dessa maneira, acreditamos que a angústia epistemológica só será realmente debelada quando ela deixar de se constituir como um problema para nós e não quando o panorama atual da produção do conhecimento se alterar.

\section{Referências}

Amorim, M. (2001). O pesquisador e ser outro: Bakthin nas Ciências Humanas. São Paulo: Musa Editora.

Aristóteles (2001). Ética a Nicômacos. (4ª ed., M. G. Cury, Trad.). Brasília: Editora da Universidade de Brasília. (Trabalho original publicado em 330a.c.)

Bauman, Z. (1999). Modernidade e ambivalência. (M. Penchel, Trad.) Rio de Janeiro: Zahar. 
Canguilhem, G. (1999). O que é a psicologia? Impulso, 11(26),1126.

Hegel, G.W.F. (1970). Encyclopédie des Sciences Philosophiques. (B. Bourgeois, Trad.). Paris: J. Vrin. (Trabalho original publicado em 1817)

Koyré, A. (2001). Do mundo fechado ao universo infinito. (D. Garschagen, Trad.). Rio de Janeiro: Forense Universitária. (Trabalho original publicado em 1957)

Latour, B. (2001). A esperança de Pandora. Bauru: EDUSC.

Lyotard, F. (2002). A condição pós-moderna. (7 $7^{\mathrm{a}}$ ed., R. C. Barbosa, Trad.). Rio de Janeiro: José Olympio.(Trabalho original publicado em 1979)
Rorty, R. (1996). Consecuencias del pragmatismo. (J. M. Cloquell, Trad.). Madrid: Tecnos. (Trabalho original publicado em 1982)

Rorty, R. (1997). Objetivismo, relativismo e verdade. Escritos Filosóficos I. (Marco Antônio Casanova, Trad). Rio de Janeiro: Relume Dumará. .(Trabalho original publicado em 1991)

Recebido em 28.03.2006

Primeira decisão editorial em 09.05.2006

Versão final em 21.08.2006

Aceito em 29.03.2007 